\title{
From the Editor and Publisher
}

$\mathrm{O}$ UR EFFORTS TO REDUCE THE LAG BETWEEN acceptance of papers for publication and their appearance on the printed page continue to gather pace. Thus, you are now reading another bumper issue of Cardiology in the Young, with a comprehensive collection of reviews, original articles, and brief reports, supplemented by 'Images in Congenital Heart Disease' and 'Clinico-Pathological Correlations'. At the same time, we are doing our very best to ensure that the issues appear on your desk synchronous with their date of publication, ideally reaching you in the week preceding the month in which publication is scheduled. This has produced some unwanted glitches, since it has not always proved possible to transmit proofs, and receive them back, so as to remove all mistakes within the tight timeframe mandated by our schedule for publication. In the January issue, this failing on our part resulted in two sets of illustrations being either transposed or printed upside down. If you didn't notice them, then so much the better! If you did, then please accept our apologies, these apologies being particularly due to the authors of the articles in which the mistakes occurred. Rest assured that we are modifying our schedules so as to ensure that future transgressions are minimal. But do also remember that mistakes occur even in the best regulated households! We are confident, nonetheless, that by the summer our issues will be appearing on time, and with few, if any, mistakes from the publication team.

We are confident that we can meet these aspirations because, already, we have accepted for publication sufficient articles and brief reports to fill our pages up to the end of the year. This policy, of course, is a two-edged sword. The more papers we hold, the more swiftly and efficiently we can prepare them for publication. But potentially at the cost of increasing the lag between acceptance and publication to which we have already referred. And if we publish all our papers, can we be sure that we will receive sufficient new manuscripts to maintain our output? The portents for future publication are good, since we continue to receive a steady flow of good manuscripts. We are well aware, nonetheless, that authors are increasingly seeking to publish their papers in journals with a significant impact factor. The importance to journals of the impact factor was emphasized in a recent editorial by Opthof on behalf of the editorial team of Cardiovascular Research. ${ }^{1}$ He made several telling comments. First, he attributed the significant increase in submission of manuscripts to their journal (more than 25\%) to the increase in impact factor from 1.47 to 3.26 over the 5 year period to 1996 . Second, he pointed to the lag between calculation of impact factor and year of publication, the impact factor for 1997 being based on papers published in 1995 and 1996. Third, he discussed ways and means of coping with the increased rate of submission without compromising their rapid time for review, and then short period between acceptance and publication. Their solution will be to reduce their rate of acceptance of papers from $35 \%$ to $30 \%$. This is a healthy state of affairs, but does raise the problem of authors being informed that their paper is rejected not on scientific grounds but because of priority. As yet, apart from brief reports, this is not a problem with which we have to cope, and we are still in the position of publishing all those original studies which are recognized by our referees as having scientific merit. Indeed, it is our policy to extract the merit even from those works in which it is, initially, well disguised! It is clear to us all, however, that our future success depends in part upon our impact factor. We are now in the process of acquiring such a factor, since the Journal is now indexed and abstracted so as to be eligible to receive this accolade. When assessing the factor as it appears, we must be cognizant of the fact that Cardiology in the Young addresses very much a 'niche' area. Furthermore, as yet we are not indexed by the National Library of Medicine in the United States of America. We have received news, nonetheless, that our submission for inclusion in Index Medicus/Medline will be considered at the June meeting of the relevant committee of the National Library. Already we have received several letters of support, and sent them on to the Committee. These will help our case immeasurably. If any of you who have not written feel constrained to offer your support, this will be gratefully acknowledged and forwarded through the appropriate channels. Please send any letters either to the Editor-in-Chief or to the Publisher.

Finally, hawk-eyed readers will notice that there is no follow-up from the Association for European Paediatric Cardiology in this issue. There is nothing sinister in this deficiency. Simply that the Editor-in-Chief and the Secretary-General of the Association were unsynchronized in their preparations. We hope to have several matters to discuss in our next issue, and also to carry a supplement with the Abstracts from the Dublin meeting, to be held from June 10 through 13 , as well as bringing you the text of the Mannheimer Lecture to be delivered by Elliot Shinebourne.

Robert H. Anderson. G. William Henry. Geoffrey L. Nuttall

\section{Reference}

1. Opthof T. How to handle an over $25 \%$ increase in submissıons. Cardıovascular Research 1998; 37: 1-2 